\title{
The analysis of vertical displacements in Upper Silesian Coal Basin area using DInSAR and PSInSAR methods
}

\author{
Michał Kniotek, Michał Lupa, Przemysław Lisowski
}

AGH University of Science and Technology, Faculty of Geology, Geophysics and Environmental Protection, Department of Geoinformatics and Applied Computer Science; al. Mickiewicza 30, 30-059 Krakow, Poland; e-mail:kniotek@agh.edu.pl,mlupa@agh.edu.pl,plisowski@geol.agh.edu.pl

(c) 2015 Authors. This is an open access publication, which can be used, distributed and reproduced in any medium according to the Creative Commons CC-BY 4.0 License requiring that the original work has been properly cited.

The main goal of this study is an analysis of vertical displacements in Upper Silesian Coal Basin (USCB) using two satellite radar interferometry methods: Differential Interferometry Synthetic Aperture Radar (DInSAR) and Persistent Scatterer Interferometric Synthetic Aperture Radar (PSInSAR) (Ferretti et al. 2007). To detect ground deformations using the PSInSAR method many satellite images (even tens) are needed, while using the DInSAR method, a pair of satellite images is needed. Satellite images are provided inter alia by European Space Agency and were obtained between 1990-2001 (PSInSAR) and 1996-2001 (DInSAR) by ERS-2 satellite. The USCB is located in south-western Poland and is highly industrialized and densely inhabited region, because of the presence of many active underground stone coal mines. Vertical displacements presented in work are conducted by underground mining exploitation and neotectonic movements. In the main, the DInSAR method allows detecting big (a few or several centimeters) and intensive (formed in a few days, 35-140 days) vertical displacements on a big area in the same time. The PSInSAR method in the main allows detecting small and permanent vertical displacements (Leśniak \& Porzycka 2008), which are correlated with neotectonic movements. It is noteworthy that results obtained using the PSInSAR method have low coherence in the areas of vertical displacements detected by using the DInSAR method. Big and intensive vertical displacements are not detected while using the PSInSAR method. Only using both methods (DInSAR and PSInSAR) allows generating a complex map of vertical displacements, which is essential for the realization of local zoning plans in the USCB area. Obtained in this work map of vertical displacements is collated with: (1) seismic data from Główny Instytut Geologiczny (GIG), (2) locations of mines in the USCB, (3) borders of coal deposits, (4) tectonics map (Jureczka \& Kotas 1995), (5) mining extraction data from Kompania Węglowa S.A.

\section{REFERENCES}

Ferretti A., Monti-Guarnieri A., Prati C. \& Rocca F., 2007. InSAR Principles: Guidelines for SAR Interferometry Processing and Interpretation. ESA Publications, ESTEC, Noordwijk, The Netherlands, [on-line:] http://www.esa. int/About_Us/ESA_Publications/InSAR_Principles_ Guidelines_for_SAR_Interferometry_Processing_and_ Interpretation_br_ESA_TM-19 [access: 9.04.2015].

Jureczka J. \& Kotas A., 1995. Upper Silesian Coal Basin. [in:] Zdanowski A. \& Żakowa H. (sci. ed.), The Carboniferous system in Poland, Prace Państwowego Instytutu Geologicznego, 148, PIG, Warszawa, 164-173.

Leśniak A. \& Porzycka S., 2008. Environment monitoring using satellite radar interferometry technique (PSInSAR). Polish Journal of Environmental Studies, 17, 3A, 382-387.

MIDAS database. [on-line:] http://geoportal.pgi.gov.pl/portal/page/portal/MIDASGIS/start [access: 9.04.2015].

Rocca F., DINSAR: Differential SAR Interferometry. [on-line:] http://earth.esa.int/landtraining07/D1LB5-1-Rocca.pdf [access: 9.04.2015]. 